\title{
SPERMATOPHORE FORMATION AND TRANSFER IN ARION LUSITANICUS MABILLE, 1868 (GASTROPODA: PULMONATA: ARIONIDAE)
}

\author{
RAFAŁ SIONEK ${ }^{1}$, JAN KOZŁOWSKI ${ }^{2}$ \\ ${ }^{1}$ Regional Plant Protection Inspectorate in Rzeszów, Langiewicza 28, 35-101 Rzeszów, Poland (e-mail: \\ sionekra@rz.onet.pl) \\ ${ }^{2}$ Department of Zoology, Institute of Plant Protection, Miczurina 20, 60-318 Poznań, Poland (e-mail: \\ J.Kozlowski@ior.poznan.pl)
}

ABSTRACT: Spermatophore formation and transfer in slugs are complex and still obscure. In the slug Arion lusitanicus Mab. the spermatophore is formed 30-35 minutes after atrium eversion; as long as the copulating slugs are connected, each spermatophore is partly in the donor's epiphallus and partly in the recipient's spermatheca duct; spermatozoa are released in the spermatheca duct 12-13 hrs after the spermatophore transfer; the spermatophore tunicle in the spermatheca dissolves within 48-72 hrs.

KEY WORDS: slugs, Arion lusitanicus, spermatophore

\section{INTRODUCTION}

Spermatophore formation during slug courtship and copulation is very complex and still incompletely understood. It varies between species. Spermatozoa may be transferred as sperm packets or enclosed in spermatophores whose shape is usually speciesspecific (WikTOR 1960, 1987, SHIKOV 1978). Spermatophore formation and movement in the efferent ducts following copulation in Arion lusitanicus Mabille, 1868 have not been explained in detail previ-

\section{MATERIAL AND METHODS}

In order to observe the moment of spermatophore appearance in the reproductive organs of A. lusitanicus, we collected and preserved copulating pairs during the peak of the slug's reproductive activity, i.e. in August. The observations were carried out in 1999 and 2000, in Rzeszów (E Poland).

The slugs were collected in consecutive periods (minutes) of their courtship and copulation and preserved in $75 \%$ alcohol. Then, in the laboratory, they were checked for the presence and location of sper- ously. Information on the copulation in this species is contained, among others, in papers by QUICK (1952), DAVIES (1987) and CASTILLEJO \& RODRIGUEZ (1993), but data on the spermatophore formation and transfer are incomplete.

The objective of this study was to trace the spermatophore formation and transfer during copulation of A. lusitanicus, and its movement in the slug's efferent ducts. matophores. The stage of spermatophore production, the time of the transfer and the position of the spermatophores in the efferent ducts were noted.

The slugs were collected and preserved during the following phases of courtship and copulation: 1 . search for the partner; 2. courtship dance: a/ from the beginning to the end of circling phase; $\mathrm{b} /$ from the end of circling phase till the atrium eversion (spermatophores were localised after 30, 35, 40, 45, 50, 60, 80 minutes); 3 . from resumption of movement 
till crawling apart of the partners (spermatophore localised after 1, 45, 105 minutes and 4, 6, 13, 24, 36, 48,72 hours). Three pairs of slugs were analysed for each phase.

\section{RESULTS AND DISCUSSION}

Examination of the genitalia of slugs collected in the first two phases of courtship and copulation: searching for the partner and the first phase of courtship dance (from the beginning to the end of circling phase) revealed no presence of spermatophores in any organs.

Further observations concerned the phases from the end of circling and getting close to the partner till the atrium eversion. The mechanism of connection with the everted genitalia and then spermatophore formation are discussed below.

\section{SPERMATOPHORE FORMATION}

Following the atrium eversion, the outlets of epiphallus and spermatheca duct get close and move apart intermittently (Fig. 1). The slugs join these openings making use of negative pressure. The connection is so strong that it is difficult to separate the

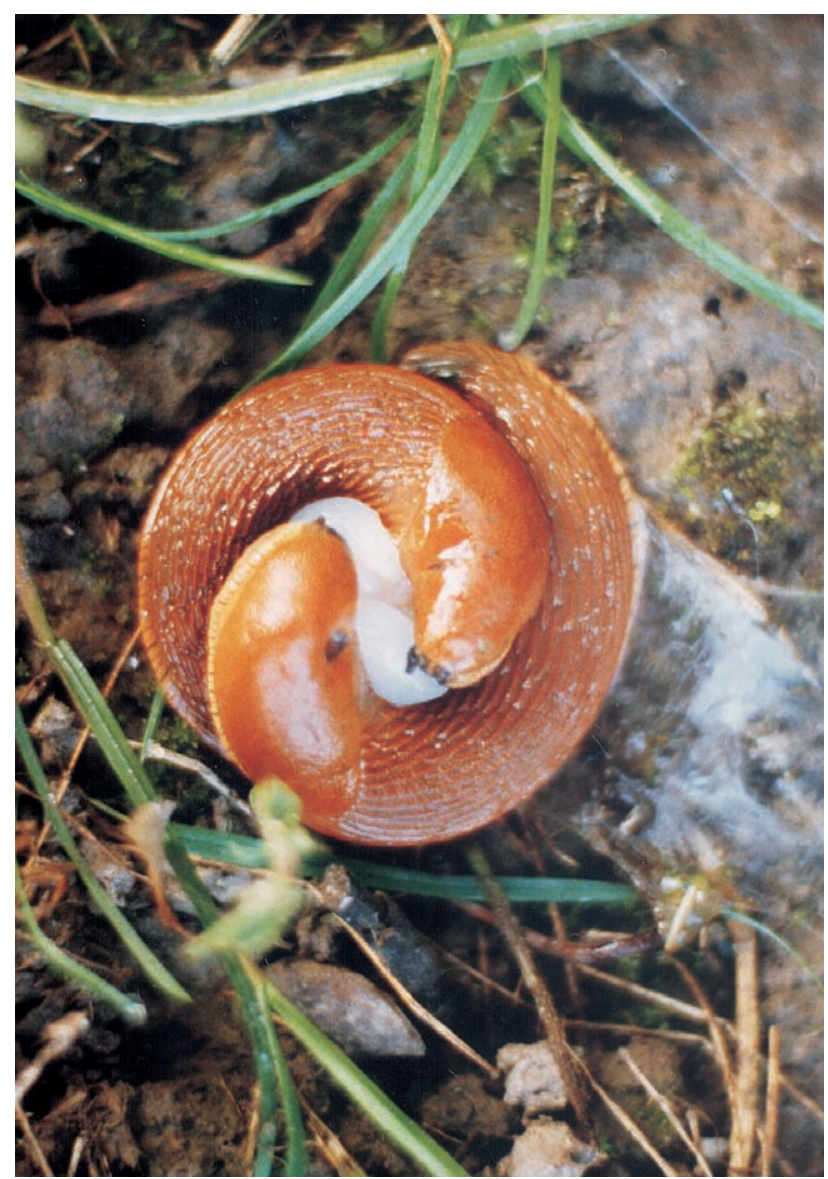

Fig. 1. Copulating A. lusitanicus; full eversion of copulatory organs (photo R. SIONEK)
Photographs of all the essential stages were taken. The terminology of the genital organs of A. lusitanicus follows RISCH \& BACKELJAU (1989) and NOBLE (1992).

partners; when preserved in this position they remain connected.

Connection of the slugs and eversion of their atria marked the beginning of their spermatophore formation, the stages of the process being the following:

- 15 minutes after the atrium eversion - no spermatophores were present;

- 20th-30th minute - a light mass of amorphous substance (not resembling a spermatophore) appeared in the epiphallus (Fig. 2);

- 30th-35th minute - the spermatophores found in the epiphallus were very poorly formed, flabby and not hardened, but had denticles on their margins. The spermatophore-containing epiphallus was strongly swollen (Figs 3, 4);

- 40th-45th minute - the spermatophores were formed and swollen but still not completely hardened, each located partly in the donor's epiphallus (1/4 length) and partly (3/4 length) in the recipient's spermatheca duct (Fig. 5). Spermatophores extracted and alcohol-preserved at that stage became twisted and misshapen;

- 50th-60th minute - the spermatophore structure and location remained unchanged;

- 60th-80th minute - the spermatophores were completely hardened, each located partly in the recipient's spermatheca duct, their position being as described above.

It follows from the above observations that the spermatophore formation starts ca. 0.5 hour after the genitalia have been everted and connected. A newly formed spermatophore has well-developed denticles on its upper margin, but is not fully filled with spermatozoa and thus flabby, not swollen. Probably the substance forming the spermatophore tunicle is the first to appear, and only then the spermatozoa penetrate. Such a "young", incompletely formed spermatophore occupies only a small portion of the epiphallus; in spite of this the epiphallus is swollen. The epiphallus walls have on their inner surface folds and sculpture that are charactersitic of the species. The shape of the spermatophore depends on this sculpture. How spermatozoa become surrounded with coagulant and if they penetrate there only after the spermatophore has been formed, could not be observed. When the first spermatophores appear, they are hardened and move to the partner's spermatheca duct. The process lasts ca. 0.5 hour and is completed ca. 60-80 minutes after connection of the genitalia of the partners. 


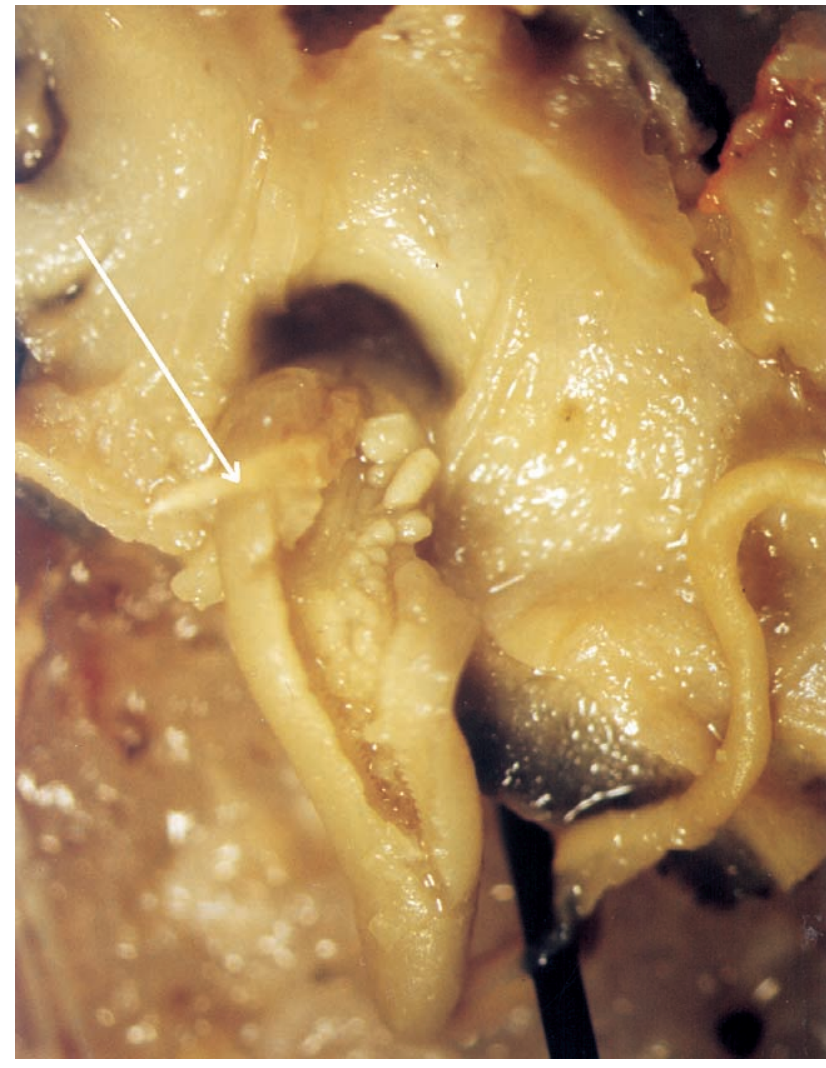

Fig. 2. Epiphallus of A. lusitanicus, slit open and containing amorphous substance; spermatophore is indicated with arrow (photo R. SIONEK)

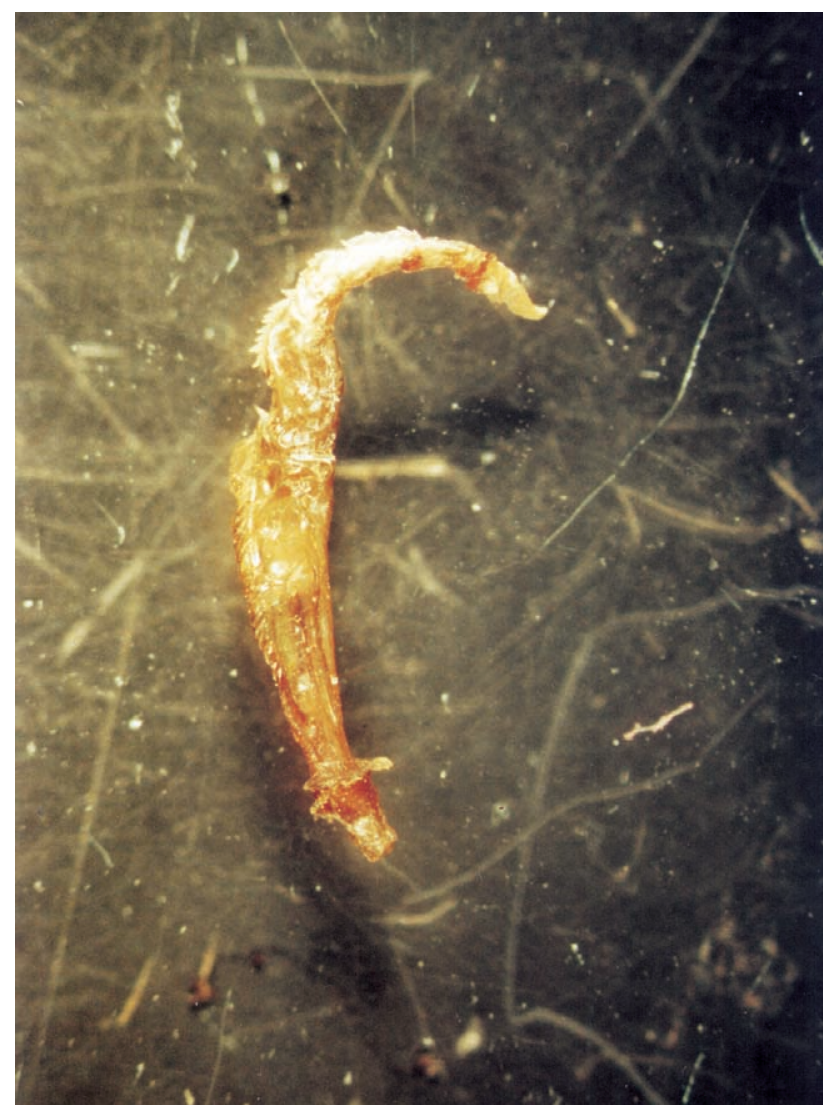

Fig. 4. An incompletely formed spermatophore of $A$. lusitanicus (photo R. SIONEK)

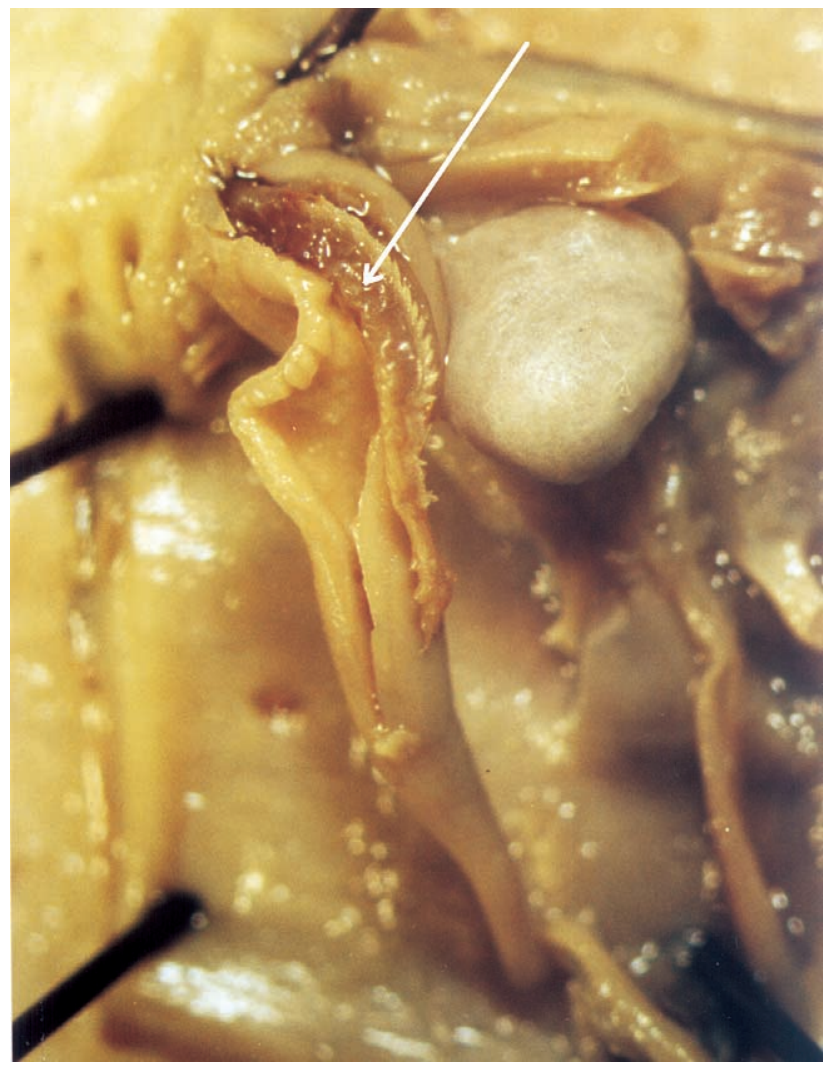

Fig. 3. Epiphallus of A. lusitanicus, slit open and containing an incompletely formed spermatophore; spermatophore is indicated with arrow (photo R. SIONEK)

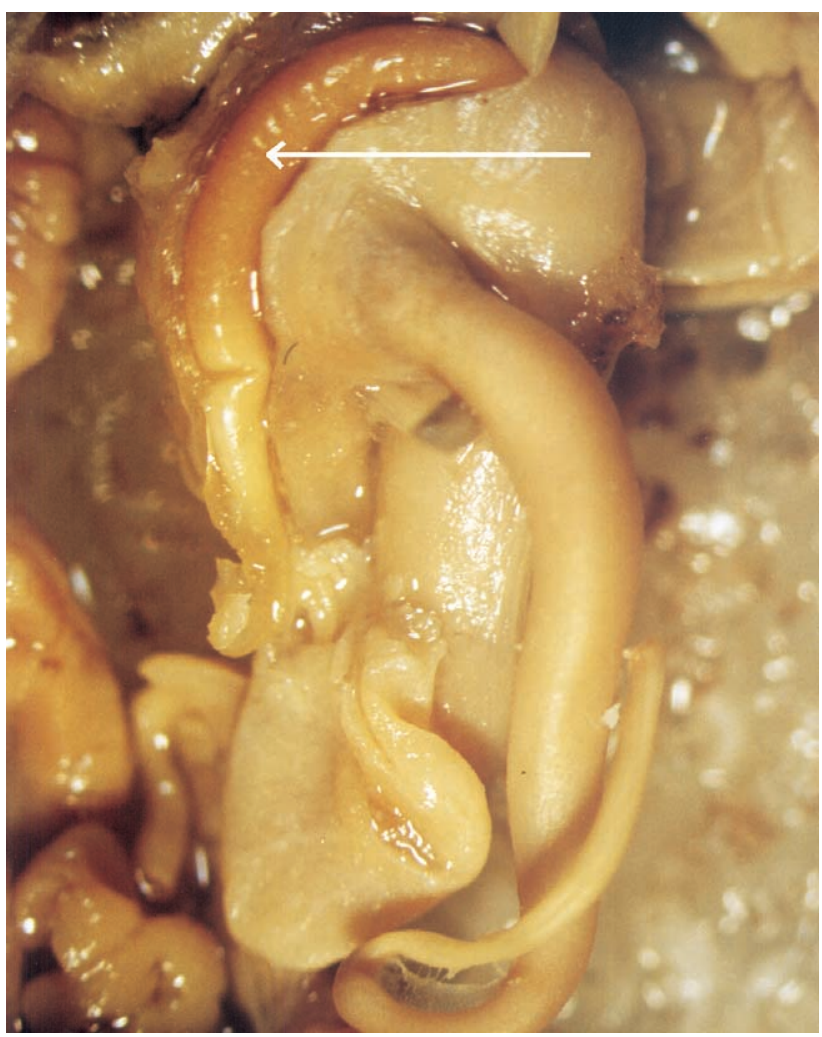

Fig. 5. Spermatophore of A. lusitanicus located partly in the donor's epiphallus and partly in the recipient's spermatheca duct; spermatophore is indicated with arrow (photo R. SIONEK) 


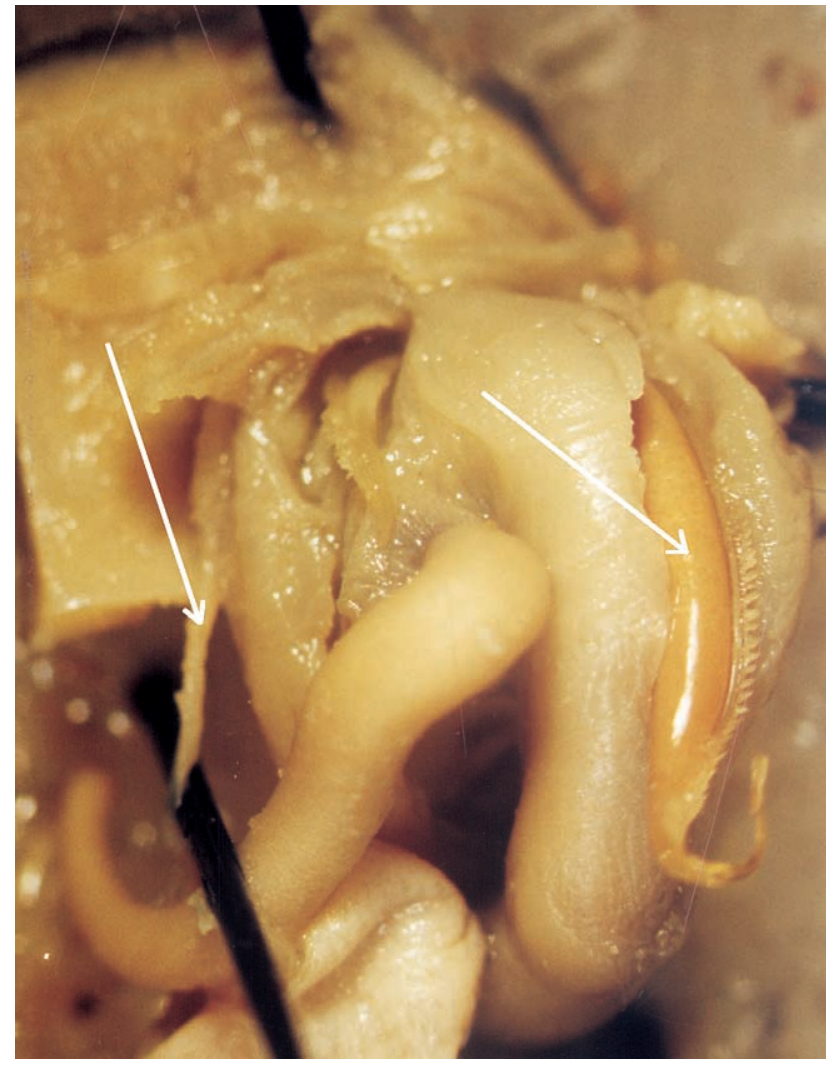

Fig. 6. Spermatophore of A. lusitanicus located partly in the recipient's oviduct and partly in the spermatheca duct; spermatophore is indicated with arrow (photo R. SIONEK)

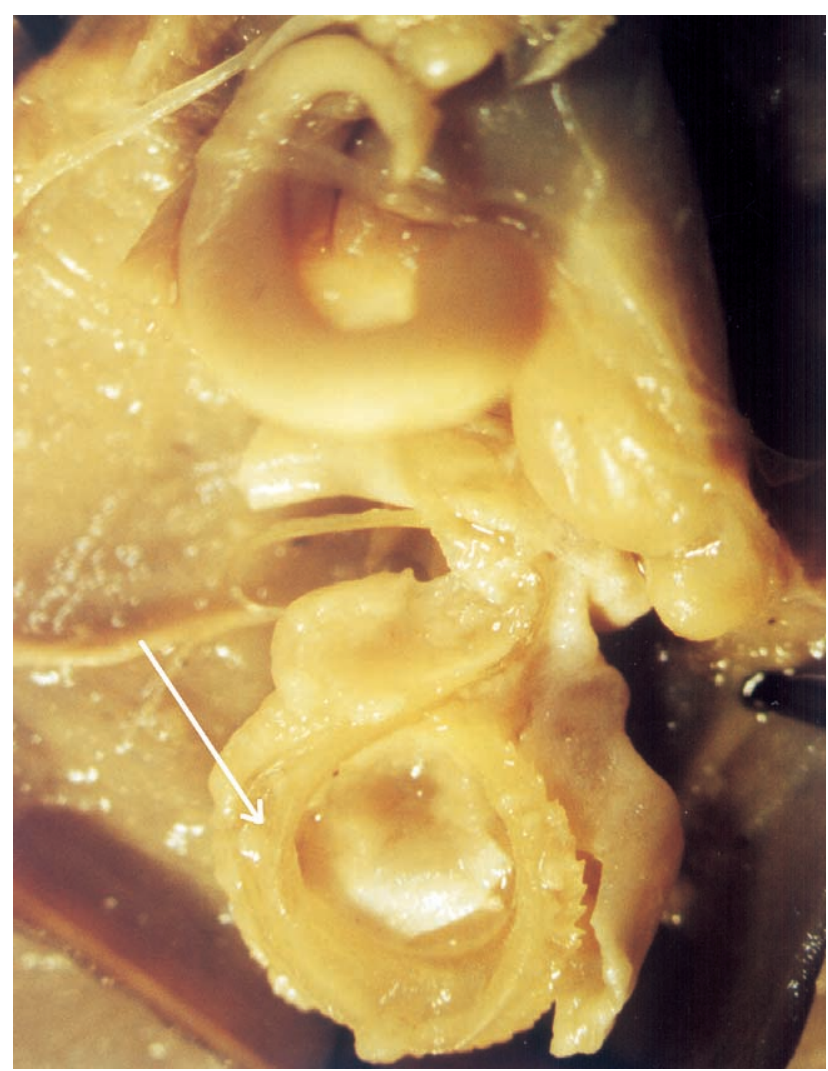

Fig. 8. A. lusitanicus. A spermatophore tunicle in the spermatheca; spermatophore is indicated with arrow (photo R. SIONEK)

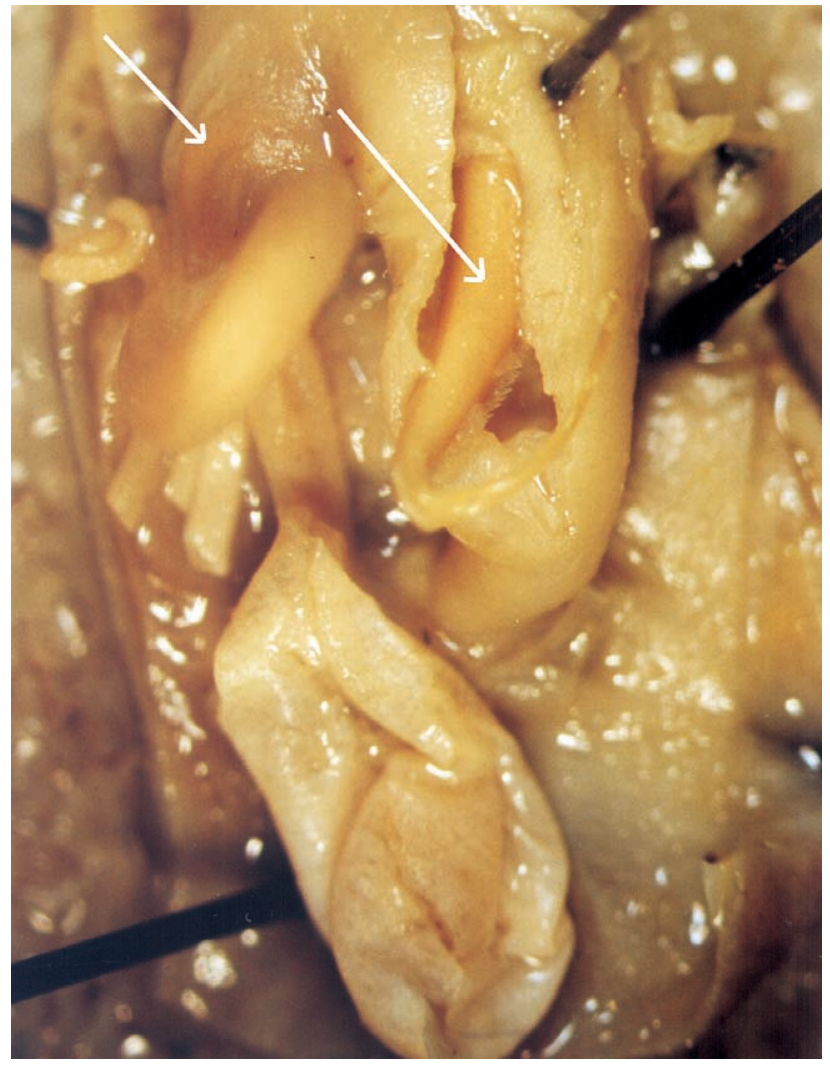

Fig. 7. Spermatophore of A. lusitanicus moving further into the recipient's spermatheca duct; spermatophore is indicated with arrow (photo R. SIONEK)

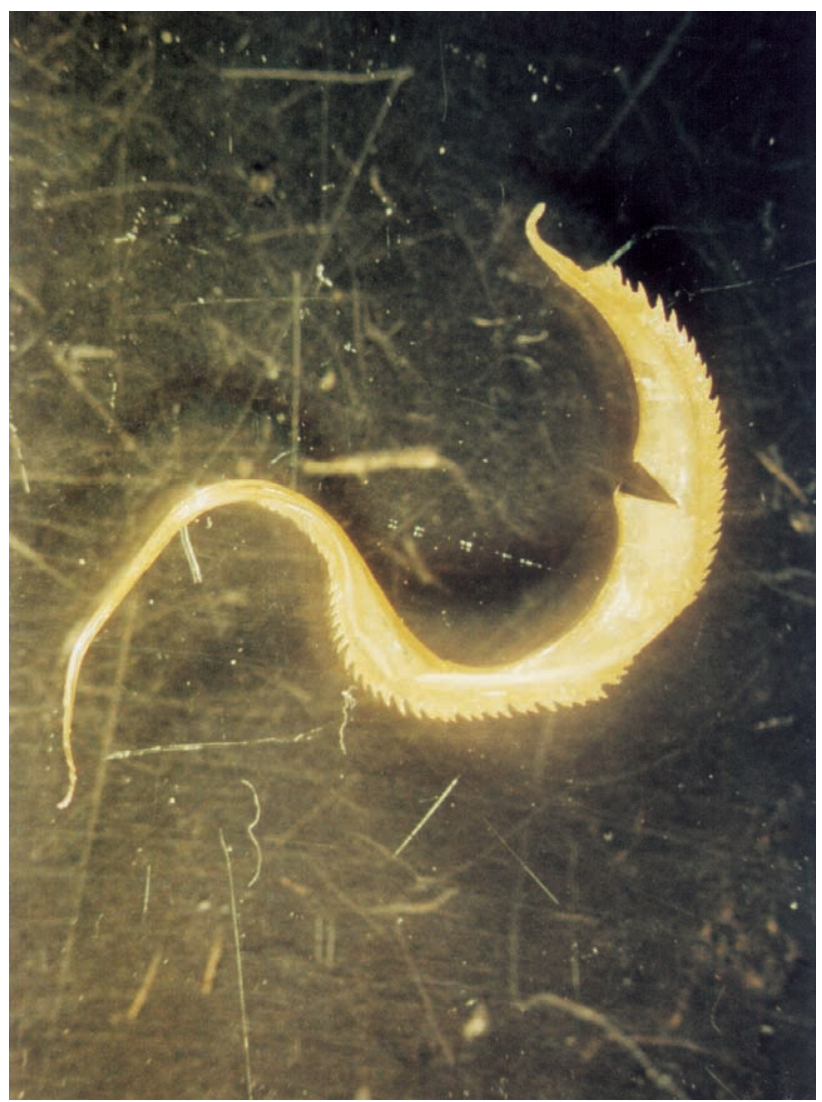

Fig. 9. A. lusitanicus. A spermatophore tunicle (photo R. SIONEK) 


\section{SPERMATOPHORE TRANSFER}

After the spermatophores have been fully formed, the atria with their adjoining structures become retracted. This takes place when the slugs crawl apart. The recipient's spermatophore is retracted together with the atrium. After the spermatophore exchange the slugs leave their mating ground. The spermatophore transfer to the partner is probably effected through negative pressure and muscular contractions which move it in the recipient's ducts. The denticles on the spermatophore are directed in a way ensuring a better anchorage in the recipient's genitalia and thus facilitating the transfer. The observed pattern of spermatophore transfer is in agreement with the general description presented by DAVIES (1987) and CASTILLEJO \& RODRIGUEZ (1993).

\section{SPERMATOPHORE MOVEMENT AND PROCESSING IN THE RECIPIENT'S GENITALIA}

After the transfer the spermatophore continues its movement in the recipient's genitalia, assuming in sequence the following positions:

- 1 minute after separation of the partners - a part of the spermatophore (2/3 length) was in the spermatheca duct, its end entering the spermatheca; the other part (ca. 1/3 length) was in the atrium, entering the proximal part of the oviduct. This thread-like termination of the spermatophore was bent and adjoined the spermatophore body. The spermatophore was visible in the translucent part of spermatheca duct. The genitalia were swollen, especially the oviduct and the spermatheca duct;

- 45 minutes after separation of the partners the spermatophore was in the oviduct but moved farther towards its distal part. Its end bent and adjoined the spermatophore body. The other end ( $1 / 6$ length of the spermatophore) was located in the spermatheca duct (Fig. 6);

- 1 hour and 45 minutes - the spermatophore was still in the oviduct and partly in the spermatheca duct;

- after 4.5 hours the spermatophore was partly (2/3 length) located in the oviduct and the atrium and partly (1/3 length) in the spermatheca duct. There was a visible swelling of these organs, indicating the spermatophore presence (Fig. 7);

- after 13 hours - the spermatophore was located in the region of the proximal part of the oviduct and partly the spermatheca duct; it was flabby and losing spermatozoa which, released, moved to the spermatheca. The oviduct and atrium were still swollen, and the epiphallus thin;

- after 24 hours - the spermatophore moved to the spermatheca and at that time the latter contained its coiled tunicle. In most individuals empty spermatophore tunicles were found in the spermatheca which was also filled with a light, jelly-like mass. Externally, a characteristically rounded shape of the spermatheca indicated the presence of the spermatophore (Fig. 8);

- after 36 hours - spermathecae of some individuals contained coiled empty tunicles (Fig. 9) of spermatophores and a light jelly-like mass, or fragments of tunicle (Fig. 10);

- after 48 hours - no spermatophore was present in the spermatheca; only in few individuals remnants of spermatophore tunicle at a stage of advanced dissolution were observed;

- after 72 hours - the spermatheca contained no fragments of spermatophores, at most, sporadically, remnants of tunicles.

The observations indicate that the spermatophore processing in the recipient's organs is complex and long-lasting. Its purpose is a proper location of the spermatophore in the genitalia and preparing it to release spermatozoa. Thirteen hours after separation of the copulating slugs the spermatophore is partly in the spermatheca duct where it bursts and starts releasing spermatozoa which enter the spermatheca. The process of spermatozoa release is quickly terminated, while the spermatophore tunicle enters the

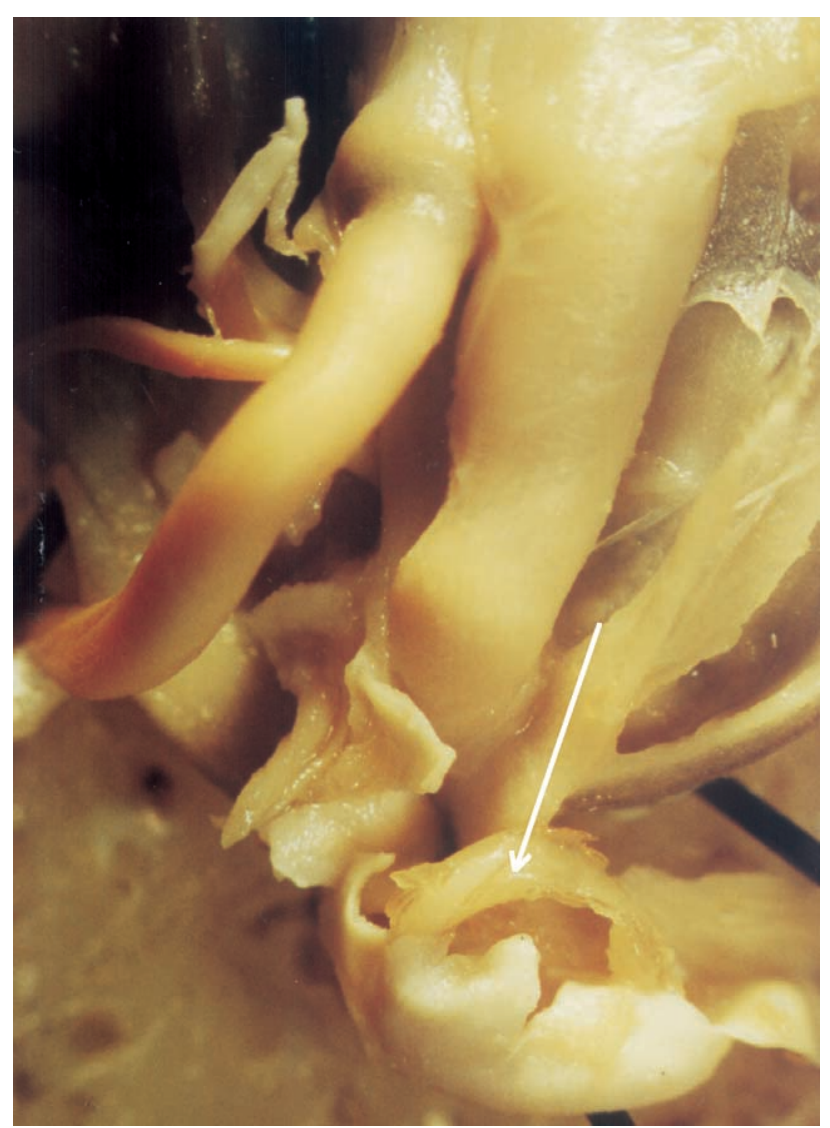

Fig. 10. A. lusitanicus. A spermatophore tunicle dissolving in the spermatheca; spermatophore is indicated with arrow (photo R. SIONEK) 
spermatheca, where within ca. 35 hours from the spermatophore bursting it is completely dissolved.

\section{SPERMATOPHORE STRUCTURE}

A fully formed and hardened spermatophore is from 15.5 to $17.5 \mathrm{~mm}$ long (measured along the midline) and $1.4 \mathrm{~mm}$ wide (widest place). It is spirally coiled; a widened spermatophore body can be distinguished, from 9.5 to $10 \mathrm{~mm}$ long, containing the spermatozoa. The ends of the body on both sides pass into elongate thread-like terminations (Fig. 11). The anterior end, entering the recipient's spermatheca duct, is 4-5 $\mathrm{mm}$ long and bent outwards relative to the spiral. The other end is shorter $(2.5-3 \mathrm{~mm})$, also bent outwards, especially its terminal section. The denticulation on the outer margin of the spermatophore starts just posterior to its anterior part and ends just posterior to the body. The protruding denticles are directed posteriorly. In the anterior and posterior parts of the spermatophore the denticles are smaller, in the part of the body containing the spermatozoa they are

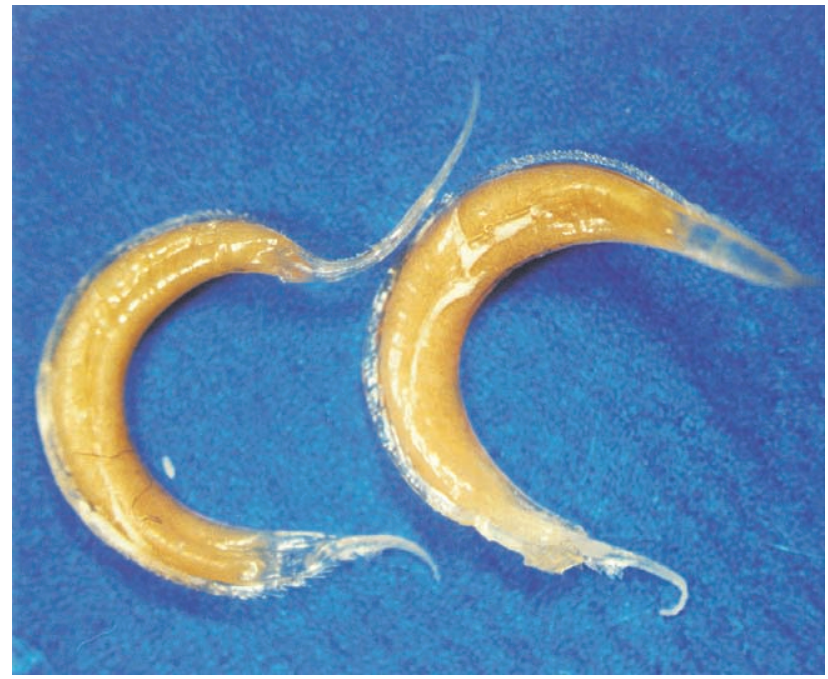

Fig. 11. A. lusitanicus. Fully formed spermatophores (photo R. SIONEK)

larger. The spermatophore structure observed by us is in agreement with the description and illustrations presented by DAVIES (1987).

\section{CONCLUSIONS}

1. In the slug Arion lusitanicus the spermatophore is formed 30-35 minutes after the atrium eversion. When the slugs are connected, each spermatophore is partly in the donor's epiphallus and partly in the recipient's spermatheca duct.

2. After the separation of the partners, a part of the spermatophore (2/3 length) is in the spermatheca duct, and its end in the spermatheca, while the other part ( $1 / 3$ length $)$ is in the atrium and the proximal part of the oviduct.

\section{REFERENCES}

CASTILlejo J., Rodriguez T. 1993. Les especies del genero Arion Férussac, 1918 en Portugal (Gastropoda, Pulmonata: Arionidae). Graellsia 49: 16-37.

DAVIES M. S. 1987. Arion flagellus Collinge and A. lusitanicus Mabille in the British Isles: A morphological, biological and taxonomic investigation. J. Conch. 32: 339-354.

NOBLE L. R. 1992. Differentiation of large arionid slugs (Mollusca, Pulmonata) using ligula morphology. Zool. Scripta 21: 255-263.

RISCH P., BACKELJAU T. 1989. On the occurrence of Arion lusitanicus Mabille, 1868 in Belgium (Mollusca: Pulmonata). Ann. Soc. R. zool. Belg. 118: 25-38.

SHIKOV E. V. 1978. Beschreibung der Spermatophore von Ena montana (Draparnaud). Arch. Moll. 109: 59-61.

3. The release of spermatozoa takes place in the spermatheca duct 12 to 13 hours from the spermatophore transfer, while its tunicle moves to the spermatheca within 24 hours.

4. A complete dissolution of the spermatophore tunicle in the spermatheca takes place $48-72$ hours after the spermatophore transfer, depending on the individual.

QUiCK H. E. 1952. Rediscovery of Arion lusitanicus Mabille in Britain. Proc. Malac. Soc. Lond. 29: 93-101.

WIKTOR A. 1960. Kopulacja pomrowa plamistego Deroceras reticulatum Müll. (Mollusca, Pulmonata). Pr. Kom. Biol. PTPN 19: 23-30.

WIKTOR A. 1987. Spermatophores in Milacidae and their significance for classification (Gastropoda, Pulmonata). Malak. Abh. 12: 85-100.

received: May 15th, 2001 accepted: August 10th, 2001 